\title{
Simulación numérica del proceso de fractura en modo I de vigas de concreto con trayectoria de fisuración conocida mediante un modelo discreto de fisura cohesiva
}

\section{Numerical modeling of the fracture process in mode I of concrete beams with known cracking path by means of a discrete model of cohesive crack}

\author{
Rubén Graffe*1, Dorian Linero* \\ * Universidad Nacional de Colombia . COLOM BIA \\ Resumen \\ Fecha de recepción: 11/ 08/2010 \\ Fecha de aceptación: 12/11/2010 \\ PAG. $399-418$
}

Este trabajo describe la formulación, implementación y aplicación de un modelo discreto de fisura cohesiva el cual permite simular el proceso de fractura en modo I de vigas de concreto simple cuya trayectoria de fisuración está definida. En el proceso de fractura se establece una relación entre el esfuerzo normal de cohesión y la apertura de una fisura, donde el material ubicado fuera de la zona de fractura conserva un comportamiento elástico lineal en carga o descarga, mientras que el material en el interior de la zona de fractura tiene un comportamiento inelástico con ablandamiento por deformación. En la malla se ubican parejas de nudos en la misma posición espacial sobre la trayectoria de la fisura, las cuales desligan a los elementos bidimensionales contiguos. Estos nudos duplicados están conectados entre sí por resortes elasto - plásticos que representan el proceso de fractura. Se simulan numéricamente tres vigas de concreto de diferentes dimensiones que soportan una carga en el centro de la luz. Cada simulación es un análisis no lineal estático con elementos finitos en condición plana de esfuerzos, considerando deformaciones infinitesimales y aplicando un desplazamiento vertical incremental sobre la cara superior de la mitad de la luz de la viga. Se obtuvieron resultados satisfactorios de la respuesta estructural de las vigas, en comparación con los ensayos experimentales y modelaciones numéricas desarrolladas por otros autores.

Palabras Clave: Análisis estructural, mecánica de la fractura, mecánica computacional, vigas de concreto, elementos finitos.

Abstract

This work describes the formulation, implementation and application of a cohesive crack discrete model, which can simulate the fracture process in mode I of simple concrete beams with defined cracking pattern. In the fracture process, a relationship between the cohesive normal stress and crack opening is established, where the material outside the fracture zone has a lineal elastic behavior in loading and unloading, whereas the material inside the fracture zone has an inelastic behavior with strain softening. In the mesh, pairs of nodes at the same spatial position are put on the cracking pattern and disconnect the adjoining two-dimensional elements. These duplicated nodes are connected to elasto-plastic springs that represent fracture process. Three concrete beams subjected to load at the middle with different dimensions are numerically simulated. Each numerical simulation is a nonlinear finite elements analysis in plane stress state, considering infinitesimal strain and applying an incremental vertical displacement on the top side of the mid-span of the beam. Satisfactory results of the structural response are obtained, as compared with experimental tests and numerical modeling carried out by other authors.

Keywords: Structural analysis, fracture mechanics, computational mechanics, concrete beams, finite element.

\section{Introduction}

Numerical modeling of concrete mechanical behavior has two typical methodologies describing fracture process zone. The first approach known as discrete crack methodology considers that the whole fracture zone is centered in one crack line and it is characterized by a stress - strain law that provokes a softening effect.

\footnotetext{
1 Autor de correspondencia / Corresponding author:

E-mail: rubengraffe@ingetec.com.co
} 
The second or, distributed crack methodology establishes that inelastic strain located in the fracture zone is distributed in a panel strip with defined width, which is imaginarily located in front of main crack (Bazant and Planas, 1998). Cohesive crack models are based on the first methodology.

In the 60's Dudgale (1960) and Barenblatt (1962) introduced the first cohesive crack models, which intended to represent the non-linear behavior placed in front of a known crack path in mode I, i.e., when crack sides are diverted in perpendicular direction from crack flat surface. In such models cohesive forces transferred from fracture zone to continuous elastic support are replaced by external equivalent forces, considering energy dissipation associated to crack spread phenomenon.

Thereafter, the fictitious crack model proposed by Hillerborg et al. (1976) extends cohesive crack definition, by indicating that the latter may be located at any place, without knowing its previous path. This study connects fracture mechanics concepts and finite elements method (Hughes 2000, O nate 2009). Two fundamental elements required to study concrete fracture with such model are (1) a fracture process in progress in the surrounding zone of an open crack due to strain allocation and, (2) an official codification that represents defined crack spread by means of a relation between cohesive forces and normal displacement of crack sides in the inner crack zone (Shi, 2009).

This article introduces the formulation, implementation and application of a cohesive crack discrete model, under a framework of finite element methods, which is able to simulate a fracture process in mode I for plain concrete beams whose crack path is well known (Graffe 2010). As application examples, three support beams of different dimensions are numerically simulated, which bear a support point in the center span. Results obtained are compared with experimental trials and numerical simulations developed by other authors as Lofti and Shing (1995), Sancho et al. (2007) and Alfaiate et al. (2003). 
Such model becomes the first step towards general overview of a plain concrete fracture process. The model validation shall confirm this methodology may be applied on new cohesive models of same type by considering crack paths previously unknown.

\section{Fracture zone process in cohesive crack models}

In concrete cohesive crack model, the fracture process in a material point begins when main stress is higher in such point and reaches concrete tensile strength $\sigma_{t}$ (Figure $1(a)$ ), as established by Rankine's failure criterion. Furthermore, it is assumed that normal stress on the crack surface coincides with main higher stress direction. On the other side, it is admitted that material located outside fracture zone has an isotropous, linear and elastic behavior characterized by Young E module and Poisson relation $v$.

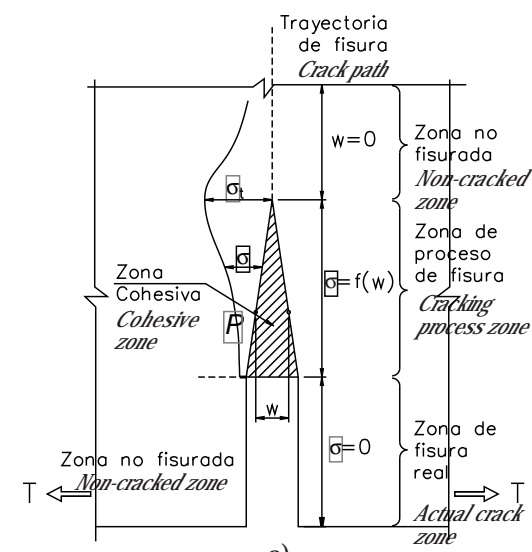

a)

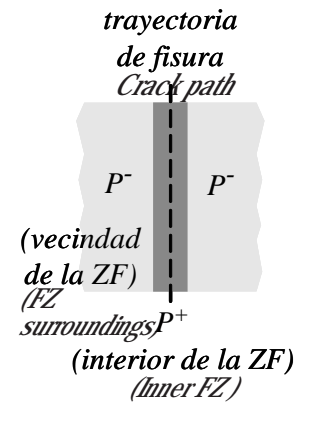

b)

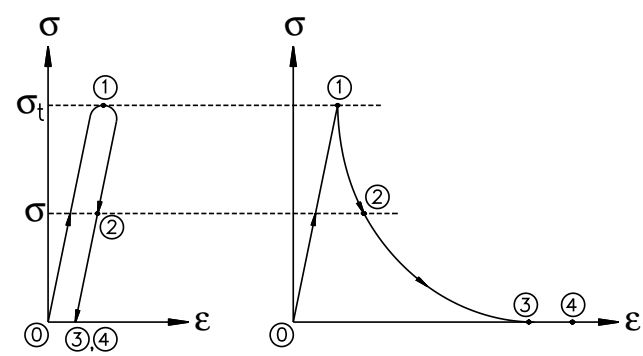

c) d)

Figura 1. Modelo de fisura cohesiva: (a) zona del proceso de fractura, (b) detalle del punto material $P$ dentro y fuera de la zona de fractura, (c) relación esfuerzo - deformación de un punto material ubicado fuera de la zona de fractura $\mathrm{P}^{-}$, y (d) relación esfuerzo - deformación de un punto material ubicado en el interior de la zona de fractura $\mathrm{P}^{+}$(Graffe 2010)

Figure 1. Cohesive crack model: (a) fracture process zone, (b) detail of material point $P$ inside and outside fracture zone, (c) relation stress - strain in a material point located outside the fracture zone $\mathrm{P}^{-}$, and stress - strain of a material point located inside the fracture zone $P^{+}$(Graffe 2010$)$ 
Where $P^{-}$and $P^{+}$are two points on the same solid material coordinate, but located outside and inside the fracture zone, respectively (Figure $1(b)$ ), which stress - strain relation are indicated in Figure 1 (c) and Figure $1(d)$. During external load application process, behavior $P^{-}$and $P^{+}$is the same until material reaches tensile stress, i.e. between points 0 and 1 of stress - strain curves. From that moment on, and between curves points 1 and 3, material in the fracture zone is softened, when strain strength increases while cohesive stress decreases, however, material outside fracture zone is elastically unloaded. This stage demonstrates that a material point surrounding is separated from strain, while normal stress continuity is kept at an orthogonal crack plane. After point 3, cohesive stress and strain outside the fracture are void, while strain keeps increasing in the crack zone.

In concrete crack process zone, in mode I, shown in Figure 1(a), the opening $w$ of the so-called cohesive crack rises progressively, while the normal strain value $\sigma$ decreases in the crack sides as follows:

$\sigma=f(w) \quad(1)$

This relation between normal strain and crack opening describes the softening effect generated by cohesion progressive loss in the fracture zone, which is called softening curve (Figure 2 (a)).

For initial opening equal zero, normal strain is equal to material tensile strength, i.e. $w=0$ and $\sigma=\sigma_{\mathrm{t}}$. However, when normal stress is void, i.e., when cohesion transmission forces among faces is lost, the presence of notorious material discontinuity called actual crack is declared, which opening keeps increasing as from critical value $w=w_{c}$.

Energy per unit area in a material point consumed as from cohesive crack arousal i.e, for and, up to actual crack formation, when $0<w \leq w_{c}$ and $0<\sigma \leq \sigma_{t^{\prime}}$ up to actual crack formation, when $w=w_{c}$ and $\sigma=0$, it is called crack specific energy or simply fracture energy $G_{F}$. Such energy is equal to integral expressed by the following equation, which corresponds to the area below softening curve, as shown in Figure 2(a). 


$$
G_{F}=\int_{0}^{w_{c}} \sigma(w) d w(2)
$$

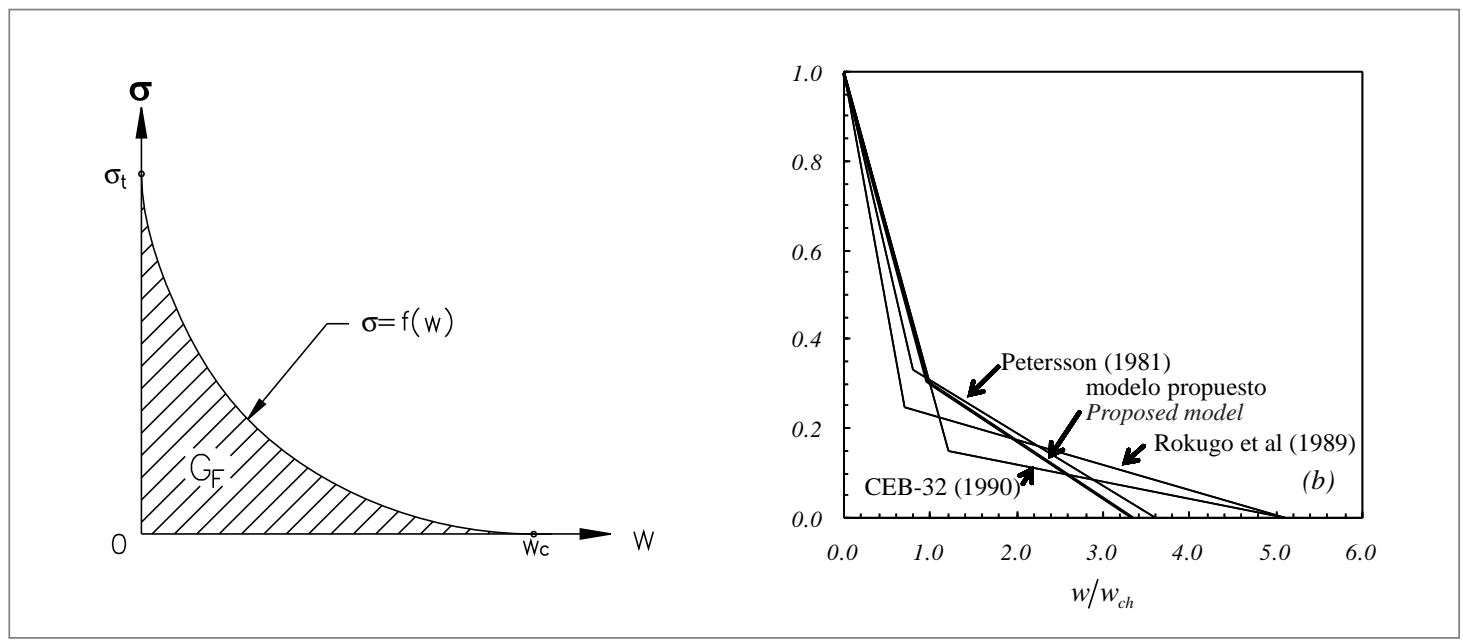

Figura 2. Modelo de fisura cohesiva, relación entre el esfuerzo normal de cohesión y la apertura de la fisura:

(a) curva general de ablandamiento, (b) curvas de ablandamiento bilineales del modelo propuesto y de diferentes autores (Bazant \& Planas 1998)

Figure 2. Cohesive crack model, relation between normal cohesive stresses and crack opening:

(a) general softening curve, (b) two-linear softening curves of model proposed by different authors (Bazant \& Planas 1998)

Fracture energy and softening curves are particular parameters of each material and their value may be determined by means of laboratory tests. Some authors have obtained $G_{F}$ values for concrete between 100 and 115 N/m (Lofti \& Shing 1995, Sancho et al., 2007; Alfaiate et al., 2003) and; simplified softening curves by means of two straight lines, as shown in Figure 2(b) (CEB 1991, Petersson 1981, Rokugo et al. 1989), where $w_{c h}=G_{F} / \sigma_{\mathrm{t}}$.

\section{Model general formulation}

N umerical model developed by this study has been implemented with the finite elements method under the following assumptions: (1) mechanical issue may be simplified with a flat stress condition, by considering infinitesimal strains and static external loads (O nate 2009); (2) only a crack in the structural element is produced, which path is previously known (Petersson 1981), (3) crack describes an opening mechanism in mode I, i.e, displacement component between crack sides is positive and perpendicular to its path (Rots 1988); (4) during fracture process a known relation is established between cohesive normal stress and crack opening (Bazant and Planas 1998); 
(5) material placed outside fracture zone maintains linear elastic behavior for load and unload, while material inside the fracture zone has an inelastic behavior with softening due to strain strength (Shi, 2009).

By means of above assumptions the fracture process in constant transverse rectangular section for plain concrete beams subjected to statically transverse loads can be represented only in one plane, which material failure is determined by flexural strength. In such experimental tests non-void stress components are contained in the beam plane describing a stress flat status; concrete shows small strain thus responding to the theory of infinitesimal strains and, flexural strength condition provokes the arousal of only one approximately vertical crack. In the same way, it has been noticed that while crack sides tend to continuously separate, the applied force is reduced, which means that material outside the fracture zone shows an approximately elastic unload.

Solid domain is divided by finite elements defined in a two-dimensional space of global coordinates

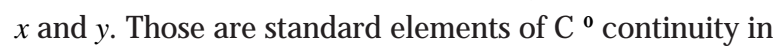
displacement field and, consequently they have two freedom degrees by node associated to longitudinal displacements in $x$ and $y$ directions (Hughes, 2000; O nate 2009), as shown in Figure 3(a) and Figure 3(b).

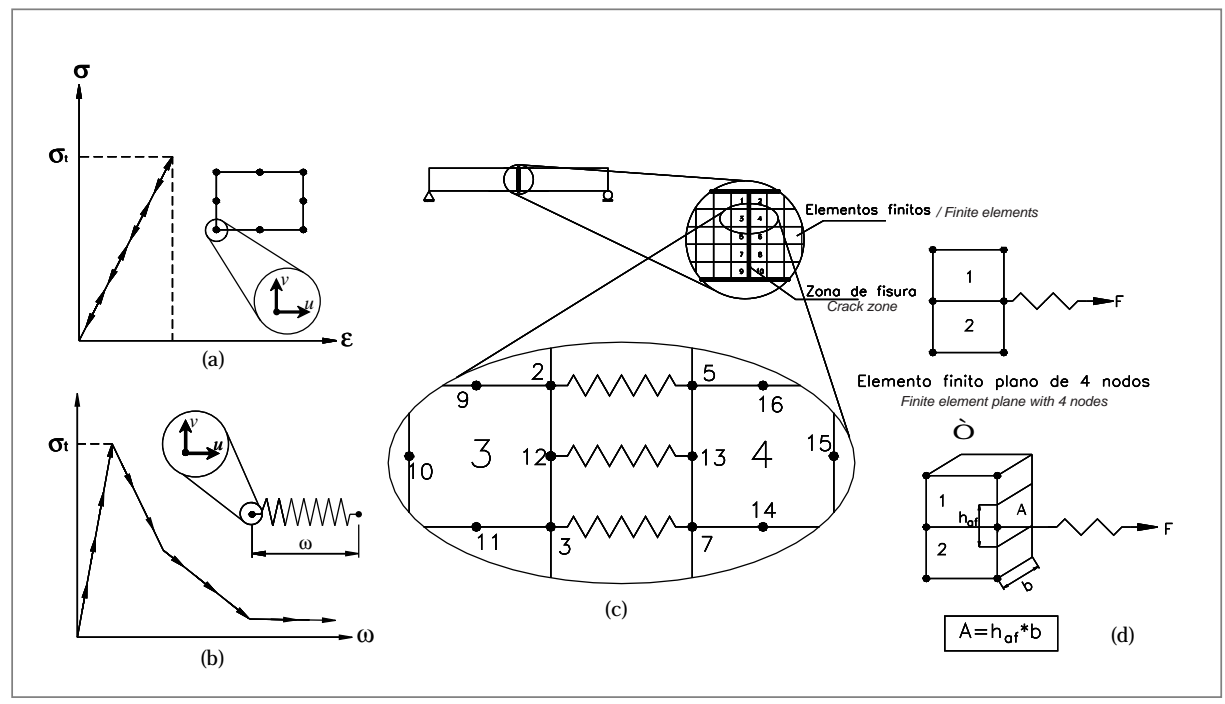

Figura 3. Tipo de elementos finitos y su relación constitutiva: (a) elemento bidimensional elástico, (b) elemento resorte elasto - plástico, (c) conexión entre elementos de la zona de fractura,

(d) área aferente del esfuerzo cohesivo en la zona de conexión entre elementos bidimensionales y resortes (G raffe 2010)

Figure 3. Type of finite elements and its constituent relation: (a) two-dimensional elastic element;

(b) elastic-plastic spring element; (c) connection between elements in the fracture zone;

(d) afferent cohesive stress area in the connection zone between two-dimensional elements and springs (G raffe 2010) 
The structure geometry is composed of twodimensional quadrilateral elements joined by nodes. Furthermore, pairs of nodes are placed in the same spatial position over the crack path, which unfasten adjoining two-dimensional elements over fracture zone. Such duplicated nodes in the same coordinate are connected each other by void dimensional springs, i.e. $e=0$, which represent the fracture process, as shown in Figure 3(c).

Two-dimensional finite elements as linear and quadratic isoparametric quadrilaterals have a linear elastic isotopic behavior and represent the material placed outside fracture zone (Figure 3(a)). Mechanical properties of such elements are Young $E$ module and concrete Poisson $v$ relation.

Softening curves parameters of numeric model are calibrated by means of experimental tests results by Petersson (1981), indicated as beam V1. Simulations conducted for concrete beams $V 2$ and $V 3$ are developed with the previously calibrated model. It is expected that softening curves parameters of numeric model are kept constant during structural elements simulation with some similar kinds of concrete.

\section{Representation of cohesive behavior in the fracture zone}

Cohesive behavior inside fracture zone is described by means of springs placed perpendicularly to crack direction, which trigger a softening plasticity constitutive relation after reaching concrete tensile strength. Elongation and strength in spring represent crack $w$ and cohesion strength $F$. Such force is obtained by the product between cohesive $\sigma$ strength and spring afferent area $A_{f}$, as follows:

$F(w)=\sigma(w) A_{f}$

Therefore spring strength $F_{t}$ resulting when cohesive strength is equal to tensile strength:

$F_{t}=\sigma_{t} A_{f} \quad(4)$ 
On the surface delimited by spring afferent area $A_{f}$, a constant normal cohesive strength equivalent to the action of internal force $F$ is distributed, as indicated in Figure 3(d). In two-dimensional problems with constant thickness $b$, the afferent area is equal to:

$A_{f}=b h_{f}(5)$

Above establishes a direct relation between the softening curve in concrete fracture zone and the idealized curve $F(w)$ between spring's strength and elongation shown in Figure 4(a).

In order to maintain the numeric solution stability in the non-lineal analysis with finite elements, an approximate relation $F(w)$ is defined for idealized curve $F(w)$, between spring's tensile strength and elongation. As shown in Figure 4(b), the approximated segment 3-4 is of an elastic stiffness $k_{2}$ with infinite trend, which ensures a full connection among two-dimensional elements before reaching material tensile strength. How ever, in segment 6-7 a quite small constant value of remaining cohesive force $\gamma F_{t}$ is maintained. Therefore, when stiffness tends to infinite in the initial stage (i.e. $K_{2} \rightarrow \infty$ ) and remaining cohesive force in the final stage tends to cero (i.e. $\gamma \rightarrow 0$ ), spring numerical model recovers the features of cohesive crack model.

O $n$ the other hand, spring shortening would indicate a non-consistent behavior where two solid regions are overlapped in the fracture zone. In order to avoid overlapping, compressive stiffness $k_{1}$ is considered as tending to infinite, i.e. segment slope 2-3. After reaching material compressive strength $\sigma_{c}$, segment 1-2 represents crushing as a branch of void stiffness.

Segments 4-5 and 5-6 describe cohesive behavior in the fracture zone, where spring stress is between $F_{4}=F_{t}$ and $F_{6}=\gamma F_{t}$. Besides, in point $6, w_{f}$ is defined as crack opening when spring strength is equal to remaining cohesive force $\gamma F_{t}$.

In order to characterize approximate curve $F(w)$ several numerical calibration were simulated on the model, supported by structural response from Petersson experimental test (1981) shown in Figure 8. Calibration results establish that point 5 corresponds to a crack opening $w_{5}=0.3 w_{f}$ and also to a cohesive force $F_{5}=0.3 \sigma_{t}$ $A_{f}$. 


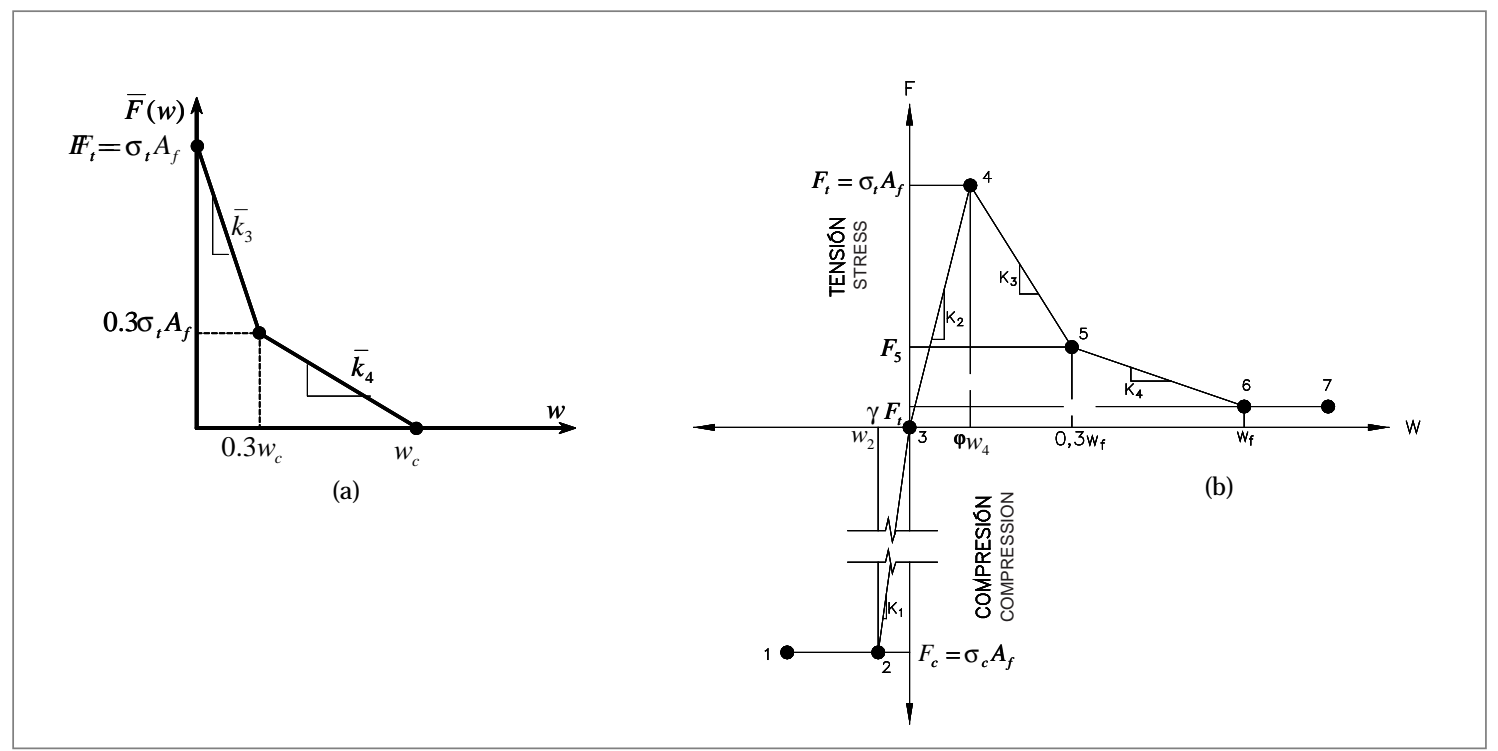

Figura 4. Relación entre la fuerza y el alargamiento del resorte: (a) curva idealizada en tracción, (b) curva aproximada en tracción y compresión utilizada en el modelo numérico Figure 4. Relation between spring strength and elongation: (a) idealized tensile curve, (b) approximate curve in tensile and compressive strengths employed by numeric model

After replacing Equation (3) in Equation (2), energy can be expressed in terms of approximate strengthelongation curve, as follows:

$$
G_{F} \cong \frac{1}{A_{f}} \int_{0}^{w_{f}} F(w) d w
$$

By replacing cohesive force function $F(w)$ in above equation, the following is obtained:

$$
G_{F} \cong \sigma_{t}\left[(0.30+0.35 \gamma) w_{f}-0.15\left(\sigma_{t} A_{f} / k_{2}\right)\right] \quad \text { (7) }
$$

Therefore, crack opening and slopes $w_{f}$ and $k_{3}$ and $k_{4}$ in the curve shown in Figure $4(\mathrm{~b})$ are equal to:

$$
\begin{gathered}
w_{f}=\frac{G_{F} / \sigma_{t}+0.15 \sigma_{t} A_{f} / k_{2}}{0.30+0.35 \gamma} \\
k_{3}=-\frac{0.70 \sigma_{t} A_{f}}{0.30 w_{f}-\sigma_{t} A_{f} / k_{2}}(9) \\
k_{4}=-\frac{(0.30-\gamma) \sigma_{t} A_{f}}{0.70 w_{f}}
\end{gathered}
$$


If $K_{2} \rightarrow \infty$ and $\gamma \rightarrow 0$, parameters, $w_{c}, k_{3}$ and $k_{4}$ are recovered from idealized curve in Figure $4(a)$, as follows:

$$
\begin{aligned}
& \lim _{\left(k_{2} \rightarrow \infty\right)(\gamma \rightarrow 0)} w_{f}=3.3333 \frac{G_{F}}{\sigma_{t}}=w_{c} \\
& \lim _{\left(k_{2} \rightarrow \infty\right)(\gamma \rightarrow 0)} k_{3}=-0.7000 \frac{\sigma_{t}^{2} A_{f}}{G_{F}}=\bar{k}_{3} \\
& \lim _{\left(k_{2} \rightarrow \infty\right)(\gamma \rightarrow 0)} k_{4}=-0.1286 \frac{\sigma_{t}^{2} A_{f}}{G_{F}}=\bar{k}_{4}
\end{aligned}
$$

Consequently, idealized softening curve employed in the numerical model proposed in this paper is defined by points $(w, \sigma)=\left(0, \sigma_{\mathrm{t}}\right),\left(w_{c h}, 0.30 \sigma_{\mathrm{t}}\right),\left(3.33 w_{c h}\right.$, 0 ), as shown in Figure 2(b). A small difference is observed in regards to the two-lineal softening curve given by points $(w, \sigma)=\left(0, \sigma_{\mathrm{t}}\right),\left(0.8 w_{c h}, 0.33 \sigma_{\mathrm{t}}\right),\left(3.60 w_{c h}, 0\right)$, analytically obtained by Petersson (1981).

Springs mechanical properties are derived from softening curve characteristics, such as concrete tensile strength ${ }_{t}$ and fracture energy $G_{F}$.

\section{Application on plain concrete beams}

The constitutive model of cohesive crack previously described may be applied to plain concrete structural elements, where crack path is known and its opening mechanism corresponds to mode I. Application examples shown below describe the behavior on three simply supported concrete beams with different dimensions, exposed to a concentrated load in the center span, as shown in Figure 5(a). Beams transverse section is rectangular and, they have a notch in center span lower side.

Each numerical simulation with finite element corresponds to a non-static linear analysis under flat stress conditions, considering infinitesimal strain and applying an increasing vertical displacement on the upper side of mid-span beam. In the same way, each application example was modeled by using several two-dimensional finite element meshes. Such simulations were developed with the commercial program ANSYS (2005). 
N on-linear source of the model is exclusively provided by the springs' elastic-plastic behavior representing fracture process.

Importance values derived from numerical simulation were compared to experimental and numeric results obtained by other authors (Lofti and Shing, 1995; Sancho et al., 2007; Alfaiate et al., 2003).

The first concrete beam simulated with the proposed model and called $V 1$, corresponds to the same structural element tested by Petersson (1981). $V 1$ has $L=2.00 \mathrm{~m}$ length, $c=0.10 \mathrm{~m}$ notch depth and, transverse section is $b=0.05 \mathrm{~m}$ base and $h=0.20 \mathrm{~m}$ height. Concrete has an $E=30 \mathrm{GPa}$ elasticity module, $v=0.15$ Poisson relation, $G_{F}=115 \mathrm{~N} / \mathrm{m}$ energy fracture, $\sigma_{\mathrm{t}}=3.33 \mathrm{MPa}$ tensile strength and approximate compressive strength.

Five different finite element mashes were developed, which beam domain was divided into twodimensional beam elements connected by means of nodes, except for the crack line. Figure 5(b) shows the first mesh called V1E4-20, because it has 20 quadrilateral finite elements and 4 nodes on the crack line, which are connected each other by springs, except in the upper node where concentrated load is applied (Figure 6 (a)) and in lower nodes which are parts of the notch (Figura 6(c))

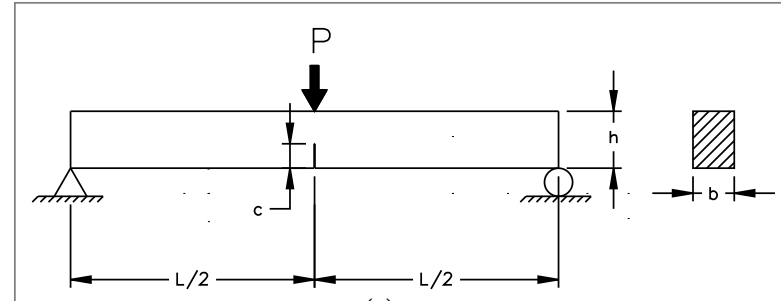

(a)
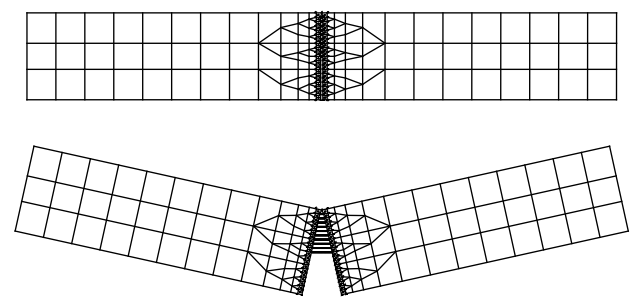

(b)

Figura 5. Vigas de concreto simple simplemente apoyadas con carga puntual en el centro de la luz:

(a) esquema general, (b) malla de elementos finitos (Graffe 2010)

Figure 5. Plain concrete beams simply supported with concentrated load in the center span:

(a) general overview, (b) finite elements mesh (Graffe 2010) 
In this particular mesh, nodes distribution between crack sides enables the consideration of the fact that afferent area is the same for all springs and, therefore, elastic - plastic relation between stress and elongation is common in each one of them. Such relation is defined in Figure 7, where segment 1-2 represents a perfect plasticity when the spring is exposed to a negative stress higher than its compressive strength. However, segments 2-3 and 3-4 show an elastic linear response with quite high slop, which tends to a stiff behavior. Fracture process is represented by spring's plastic softening as show $n$ in 4-5 and 5-6 segments, which end up with the transmission of cohesive force quite low in segment 6-7.

In the simulation 19 increases were applied for vertical displacement or strain in the mid span, each one of $0.1 \mathrm{~mm}$ until reaching a $1.9 \mathrm{~mm}$ deflection.

Beam structural response is represented by means of the applied external concentrated load $P$ and mid-span deflection $\delta$. Figure 8 indicates such result for each $\delta$ increment, where an initial elastic linear behavior limited by a maximum load is observed, followed by a load non-linear progressive reduction with deflection increase that maintains $P=0$ as asymptote. Maximum load calculated by the numerical model is 1.14 times higher than the one obtained in the experimental trial, due to low density of finite elements in the fracture zone.

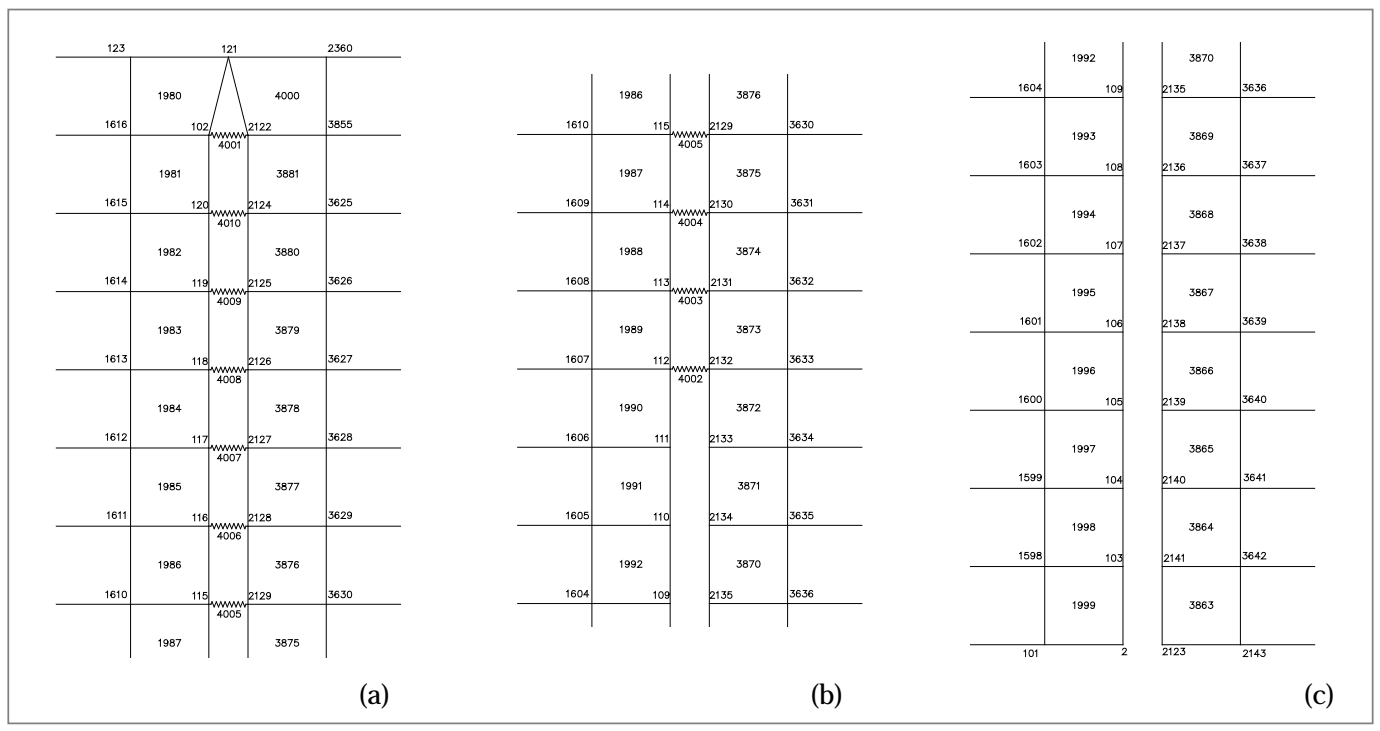

Figura 6. Detalle de la malla de elementos finitos en la zona de fractura: (a) tramo superior, (b) tramo intermedio y (c) tramo inferior Figure 6. Detail of finite elements mesh in the fracture zone: (a) upper segment, (b) Intermediate segment and (c) lower segment 


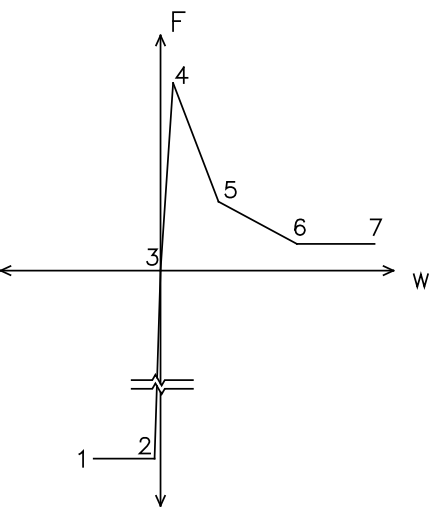

\begin{tabular}{|ccc|}
\hline Punto/Point & $\mathrm{W}(\mathrm{mm})$ & $\mathrm{F}(\mathrm{N})$ \\
\hline 1 & -1.000000 & -16650 \\
2 & -0.002220 & -16650 \\
3 & 0.000000 & 0 \\
4 & 0.000444 & 1665 \\
5 & 0.033431 & 500 \\
6 & 0.111437 & 50 \\
7 & 1.000000 & 50 \\
\hline
\end{tabular}

Figura 7. Relación Fuerza - alargamiento de los resortes: (a) gráfica, (b) tabla Figure 7. Relation stress - elongation of springs: (a) graph, (b) table

The formation of an actual crack is represented by the numerical model as the set of points where springs have lost their cohesive capacity, i.e., when stress acquires an almost void value, as depicted by 6-7 segment in Figure 7. Therefore the crack tip is placed next to the last point, which spring has already lost cohesion capacity.

During the application of vertical displacement in the simulation, the major main stress $\sigma_{1}$ is concentrated in the inner fracture zone and its surroundings, exactly in the crack tip. Figure 9 introduces $\sigma_{1}$ distribution, close to fracture zone at a fixed color scale for some displacement states, indicated by numbers in Figure 8.

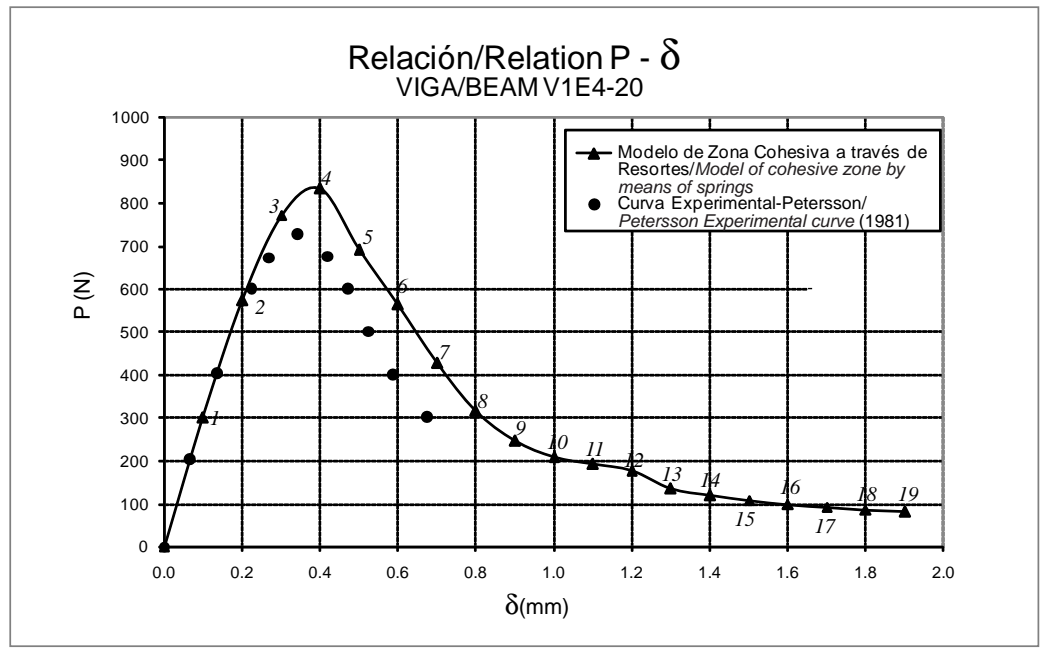

Figura 8. Relación entre la carga aplicada y la deflexión en la mitad de la luz obtenida de la simulación numérica V1E4-20 Figura 8. Relation between applied load and deflection in the mid-span obtained by numerical simulation V1E4-20 


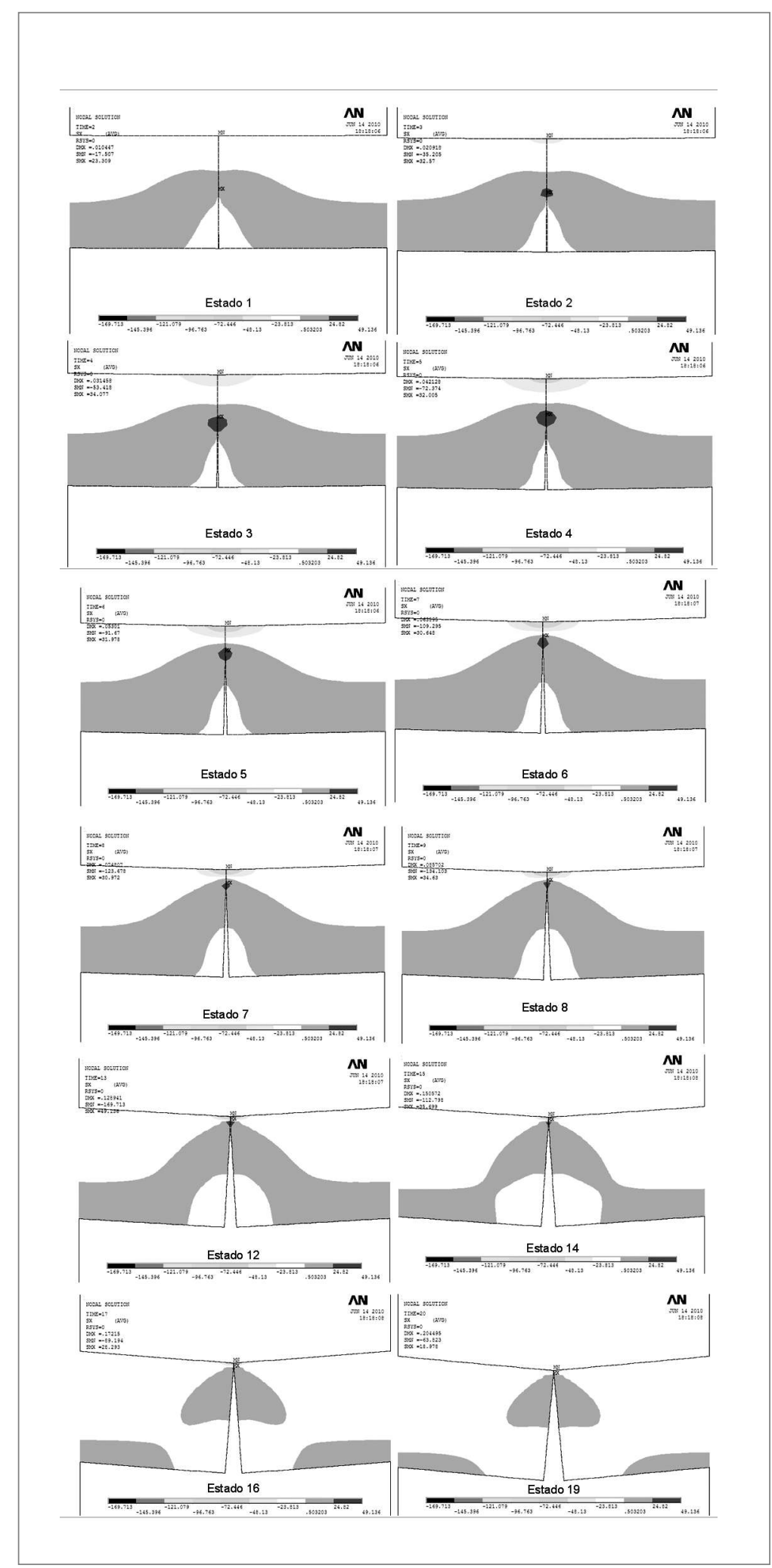

Figura 9. Evolución de la distribución del esfuerzo principal mayor obtenida de la simulación numérica V1E4-20 ( $\left.\mathrm{kg} / \mathrm{cm}^{2}\right)$ : estados $1,2,3,4,5,6,7,8,12,14,16$ y 19 Figure 9. Evolution of main major stress distribution obtained from numerical simulation V1E4-20 ( $\left.\mathrm{kg} / \mathrm{cm}^{2}\right)$ : estates $1,2,3,4,5,6,7,8,12,14,16$ and 19 
State 1 corresponds to beam elastic behavior with low stress values. In state 2 a maximum tensile stress zone comes up in the notch end, which progressively displaces upwards in 3 and 4 states. Such stress concentration bulb base is equal to concrete tensile strength, and indicates the crack pin position for each displacement state. In states from 5 to 8 , the stress displacement curve slope is negative (Figure 8 ), while the maximum tensile stress zone is close to the upper beam side (Figure 9). From states 12 to 19, resistant load is quite low and decreases softly by showing tensile stressed in the whole beam except for the upper side, where still there is a compression strength small zone. In the final states a resistant load is kept constant approximately equal to $11 \%$ maximum load since the numerical model does not assumes a compression strength limit. In such stress states main major axis direction can be considered as parallel to $x$ axis, which confirms that springs are properly placed.

The same beam was simulated by means of five different finite element meshes. Meshes called V1E4-10 and V1E4-20 have 10 and 20 quadrilateral bidimensional elements with 4 nodes in the fracture zone, respectively as shown in Figure 10. However, meshes called V1E820, V1E8-40 and V1E8-80, have 20, 40 and 80 quadrilateral bidimensional elements with 8 nodes in the fracture zone, respectively.

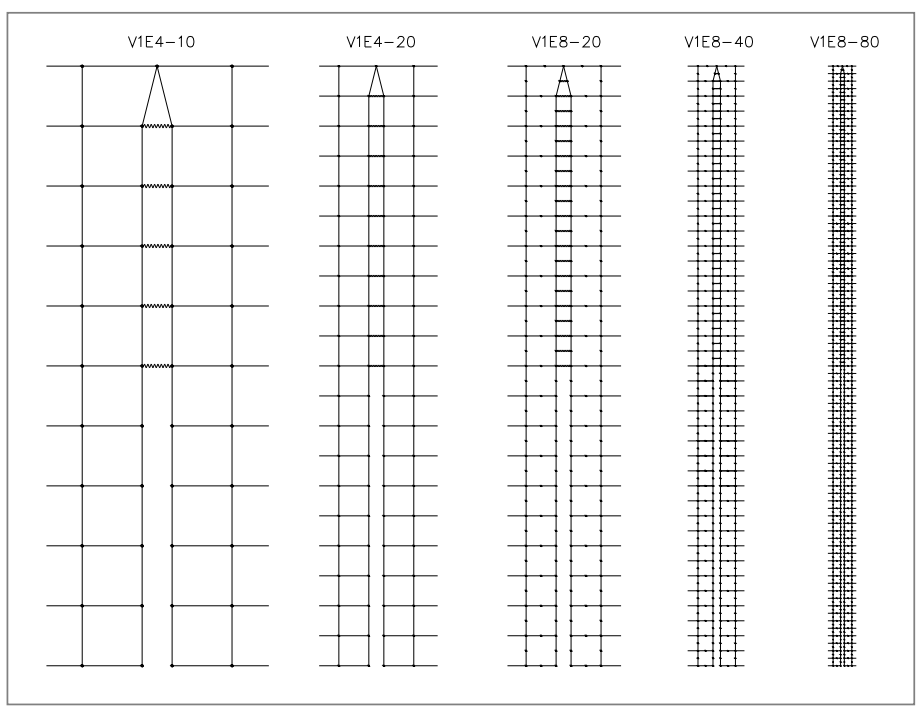

Figura 10. Detalle de las diferentes mallas de elementos finitos en la zona de fractura: (a) malla V1E4-10,

(b) malla V1E4-20, (c) malla V1E8-20, (d) malla V1E8-40 y (e) malla V1E8-80

Figure 10. Detail of different finite element meshes in the fracture zone: (a) mesh V1E4-10,

(b) mesh V1E4-20, (c) mesh V1E8-20, (d) mesh V1E8-40 and (e) mesh V1E8-80 
Figure 11 illustrates the structural response experimentally obtained by Petersson (1981); it was calculated by means of embedded crack numerical model introduced by Alfaiate et al. (2003) and obtained from different meshes in the proposed model. As long as mesh becomes finer, beam peak load gets closer to the experimental result. However, meshes V1E4-20, V1E820, V1E8-40 and V1E8-80 having more than 20 elements in the fracture zone show almost the same post peak structural response.

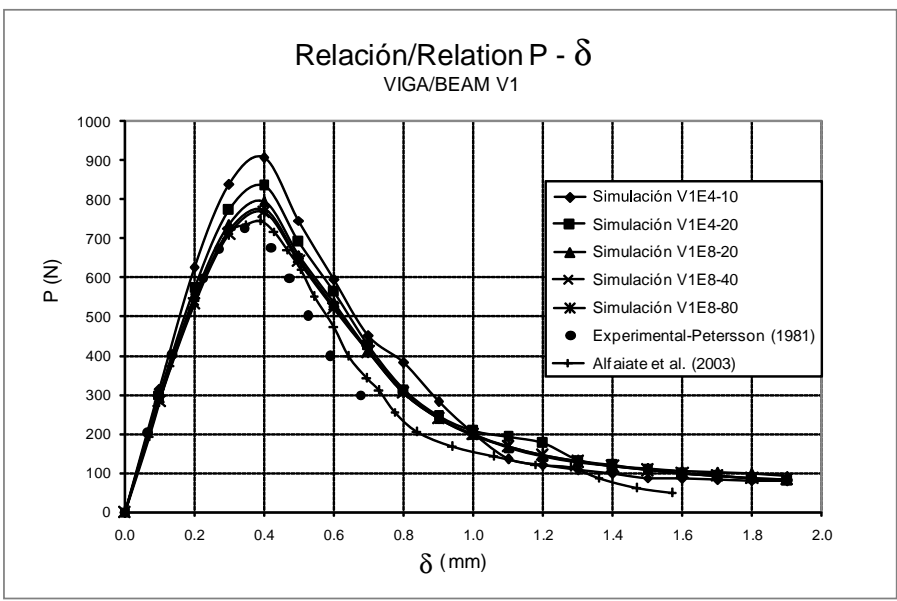

Figura 11. Relación entre la carga aplicada y la deflexión en la mitad de la luz de la viga V1, obtenidos de ensayos experimentales y simulaciones numéricas (Alfaiate et al., 2003)

Figure 11. Relation between applied load and deflection in beam mid-span V1, obtained from experimental trials and numeric simulations (Alfaiate et al. 2003)

Beam $V 2$ taken from studies by Sancho et al. (2007) has $L=2.00 \mathrm{~m}$ length, $c=0.20 \mathrm{~m}$ notch depth, transverse section of $b=0.10 \mathrm{~m}$ base and $h=0.50 \mathrm{~m}$ height. Concrete mechanical properties defined in the reference are: elasticity mode $\mathrm{E}=20 \mathrm{GPA}$, Poisson relation $v=0.15$, fracture energy $G_{F}=100 \mathrm{~N} / \mathrm{m}$ and tensile strength $\sigma_{t}=$ 2.50M Pa. In the mid-span 19 vertical displacements increases were applied, each one of $0.05 \mathrm{~mm}$ until reaching a $0.95 \mathrm{~mm}$ deflection.

Beam was simulated with four different finite element meshes. Meshes called V2E4-20 and V2E8-20 in the fracture zone have 20 quadrilateral two-dimensional elements with 4 nodes and 8 nodes, respectively. However, meshes called V2E8-50 and V2E8-100 have 50 and 100 quadrilateral two-dimensional elements with 8 nodes in the fracture zone. 
Figure 12 illustrates the structural response obtained from numerical simulation developed with cohesive crack models introduced by Sancho and collaborators (2007), and calculations from different meshes in the proposed model. Results for four meshes are similar, with load values $4 \%$ higher than solution proposed by other authors (Sancho et al., 2007).

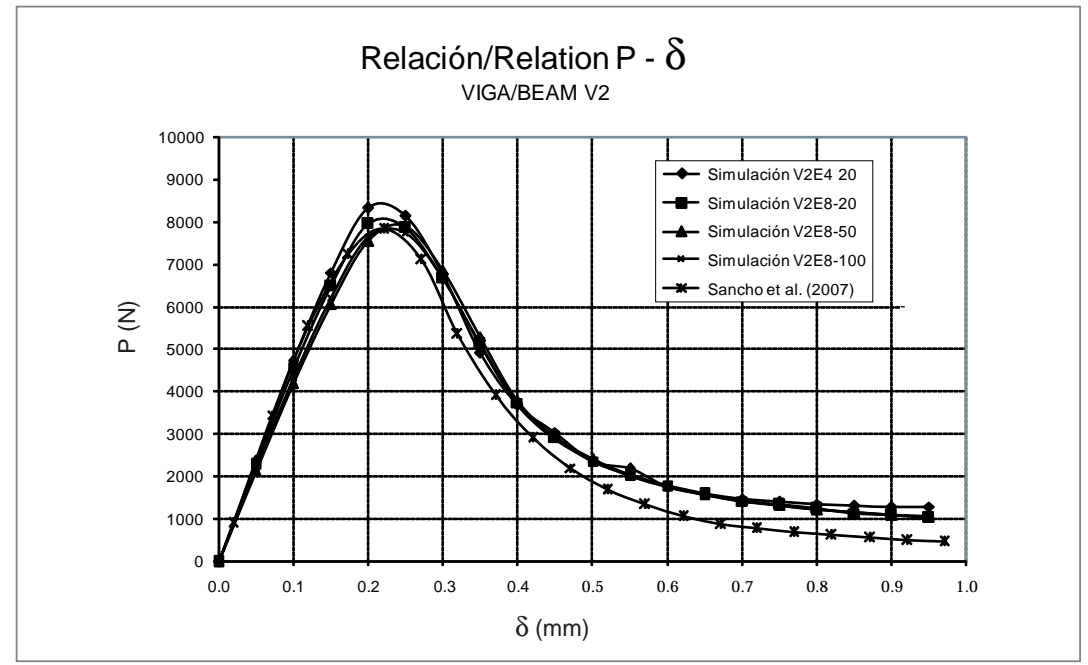

Figura 12. Relación entre la carga aplicada y la deflexión en la mitad de la luz de la viga V2, obtenidos de simulaciones numéricas con modelos de fisura cohesiva (Sancho et al., 2007)

Figure 12. Relation between applied load and deflection in beam mid-span V2, obtained from numerical simulations for cohesive crack models (Sancho et al. 2007)

Beam $V 3$ taken from experimental trials developed by Kormeling and Reinhardt (993) have $L=0.45 \mathrm{~m}$ length, $c=0.05 \mathrm{~m}$ notch depth and transverse section of $b=0.10 \mathrm{~m}$ base and $h=0.10 \mathrm{~m}$ height. Concrete has $E=20$ elasticity module, $v=0.20$ Poisson relation, $G_{F} 113 \mathrm{~N} / \mathrm{m}$ fracture energy, $\sigma_{\mathrm{t}}=2.40 \mathrm{MPa}$ tensile strength and $\sigma_{\mathrm{C}}=24.0 \mathrm{MPa}$ approximate compressive strength. In the mid-span 19 vertical displacements increases were applied, each one $0.03 \mathrm{~mm}$ until reaching a $0.57 \mathrm{~mm}$ deflection.

Beam was simulated by means of four different finite elements meshes. M eshes called V3E4-20 and V3E820 in the fracture zone have 20 quadrilateral twodimensional elements with 4 nodes and 8 nodes, respectively. However, meshes called V3E8-40 and V3E880 have 40 and 80 quadrilateral two-dimensional elements with 8 nodes in the fracture zone. 
Figure 13 illustrates the structural response obtained from experimental trials developed by Kormeling and Reinhardt (1993), from embedded crack model introduced by Lofti and Shing (1995) and from the four meshes in the proposed model. A strong coincidence is noticeable between four meshes curves however; maximum load is approximately $5 \%$ higher than ultimate limit in the experimental value. In the same way, postpeak behavior in the proposed model get closer to the numeric model introduced by other authors (Lofti and Shing 1995) and shows a higher load than experimental result.

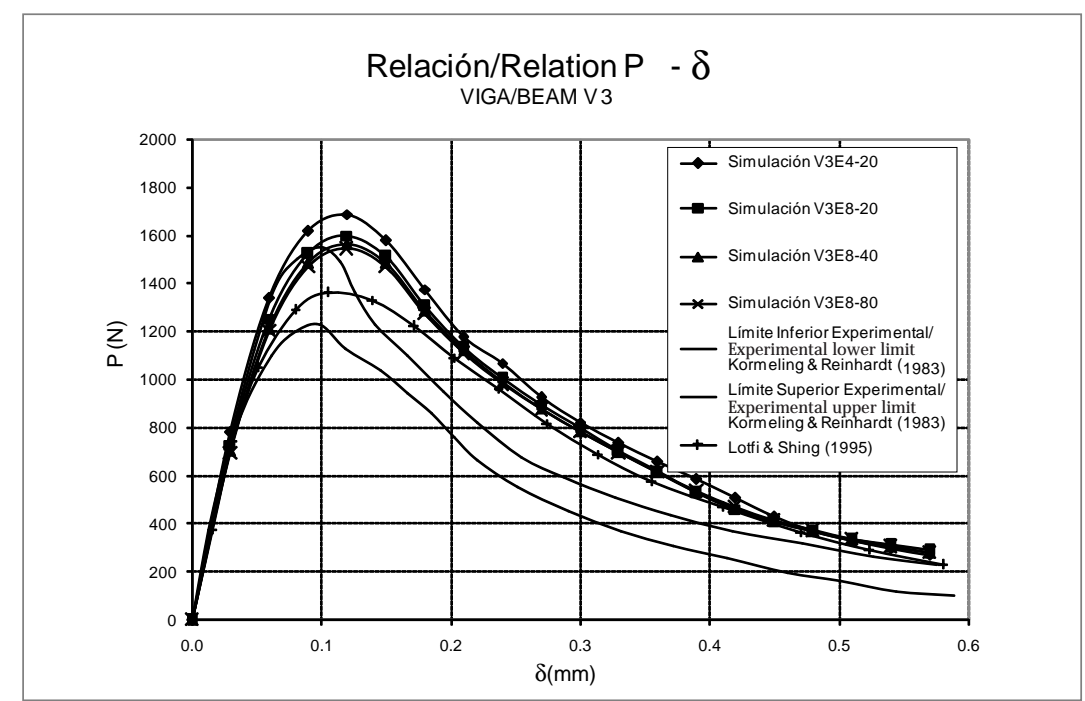

Figura 13. Relación entre la carga aplicada y la deflexión en la mitad de la luz de la viga V3, obtenidos de ensayos experimentales y simulaciones numéricas (Lotfi y Shing 1995)

Figure 13. Relation between applied load and deflection in mid-span beam V3, obtained from experimental trials and numerical simulations (Lofti and Shing 1995)

\section{Conclusions}

As general conclusion the structural behavior of plain concrete beams with known crack path and opening mechanism in mode I can be obtained by means of a discrete cohesive crack simplified model, where the fracture process is represented by means of elastic-plastic springs normal to crack path, while the rest of the structure is represented with two-dimensional elastic elements. W hen main stress reaches concrete tensile strength, springs plastic softening takes place between crack sides and elastic unload of two-dimensional finite elements in the surroundings. 
Difference between numerical and experimental structural response may be explained by the use of supposed typical values in some mechanical properties of concrete in numerical model.

Indispensable concrete mechanical properties needed to describe fracture process by the proposed model are: fracture energy, tensile strength and relation between cohesive stress and crack opening. The latter may be properly described by a two-linear curve.

In the numerical model for concrete beams, crack tip is located in the last spring surrounding which has void cohesive strength. In this point a main major stress concentration bulb was observed for concrete finite elements, which was changing with the increase of external load applied. However, softening defined by fracture zone demands such stress be equal or lower than material tensile strength.

In a beam simply supported by concentrated load in the central span, analysis results from a fracture process are close to experimental response when twodimensional finite element height is lower than $1 / 20$ of total beam height.

U nlike other cohesive crack models, this study introduces a simplified methodology to be directly applied on commercial programs of non-linear analysis with finite elements to include two-dimensional elastic elements and unidimensional elastic plastic elements in their libraries.

Such methodology offers satisfactory results on numerical simulation for one of the regulated experimental results in fracture process in mode I. Therefore it contributes and ensures the development of further complex models representing mechanical behavior of plain concrete structures with one or more unknown cracks paths. 


\section{Referencias / References}

Alfaiate J., Simone A. y Sluys L. J. (2003), A new approach to strong embedded discontinuities. EURO-C Conference 2003 Computational Modelling of Concrete Structures'. St Johann im Pongau, Austria., Taylor and Francis. ANSYS (2005), Ansys 10.0. Release 10.0 ed. United States.

Barenblatt G. (1962), The mathematical theory of equilibrium of cracks in brittle fracture. Advances in Applied Mechanics, 7 , 55-129.

Bazant Z. y Planas J. (1998), Fracture and size efect in concrete and other quasibrittle materials, CRC Press. CEB (1991), CEB-FIP Model Code 1990, Comité Euro-International du Béton.

Dugdale D. (1960), Yielding of steel sheets containing slits. Journal for Mechanics of Phisics and Solids, 8, 100-108. Graffe R. D. (2010), Simulación del proceso de fractura de vigas de concreto simple, mediante modelos de fisura cohesiva. U nidad de Posgrados. Facultad de Ingeniería Civil y Agrícola. Bogotá D.C., Universidad Nacional de Colombia.

Hillerborg A., M odeer M. y Petersson P. E. (1976), Analysis of crack formation and crack growth in concrete by means of fracture mechanics and finite elements. Cement and concrete research, 6, 773-782.

Hughes T. J. R. (2000), The finite element method, New York, Dover.

Kormeling H. A. y Reinhardt H. W. (1983), Determination of the fracture energy of normal concrete and epoxy modified concrete. Delft U niversity of Technology, Report 5-83-18.

Lotfi H. R. y Shing P. B. (1995), Embedded representation of fracture in concrete with mixed finite elements. International Journal for Numerical Methods in Engineering, 38, 1307-1325.

O ñate E. (2009), Structural Analysis with the Finite Element M ethod, CIMNE - Springer.

Petersson P. E. (1981), Crack grown and development of fracture zone in plain concrete and similar materials. Lund, Swenden, Division of Building Materials, Lund Institute of Technology.

Rokugo K., Iwasa M., Suzuki T. y Koyanagi W. (1989), Testing methods to determine tensile strain softening curve and fracture energy of concrete. Fracture Toughness and Fracture energy: Test Methods for Concrete and Rock. Rotterdam, Balkema. Rots J. G. (1988), Computational Modeling of Concrete Fracture, University of Delf.

Sancho J. M., Planas J., Cendón D., Reyes E. y Gálvez J. (2007), An embedded crack model for finite element analysis of concrete fracture. Engineering Fracture Mechanics, 74, 75-86.

Shi Z. (2009), Crack Analysis in Structural Concrete, Burlington, USA, Butterworth-Heinemann Elsevier. 